\title{
Role of a novel disulfide bridge within the all-beta fold of soluble Rieske proteins
}

\author{
Hugo M. Botelho · Sónia S. Leal • Andreas Veith · \\ Vesna Prosinecki - Christian Bauer · Renate Fröhlich • \\ Arnulf Kletzin • Cláudio M. Gomes
}

Received: 20 July 2009/ Accepted: 4 October 2009/Published online: 28 October 2009

(C) SBIC 2009

\begin{abstract}
Rieske proteins and Rieske ferredoxins are present in the three domains of life and are involved in a variety of cellular processes. Despite their functional diversity, these small $\mathrm{Fe}-\mathrm{S}$ proteins contain a highly conserved all- $\beta$ fold, which harbors a [2Fe-2S] Rieske center. We have identified a novel subtype of Rieske ferredoxins present in hyperthermophilic archaea, in which a twocysteine conserved $\operatorname{SKTPCX}_{(2-3)} \mathrm{C}$ motif is found at the $\mathrm{C}$-terminus. We establish that in the Acidianus ambivalens representative, Rieske ferredoxin $2(\mathrm{RFd} 2)$, these cysteines form a novel disulfide bond within the Rieske fold, which can be selectively broken under mild reducing conditions insufficient to reduce the $[2 \mathrm{Fe}-2 \mathrm{~S}]$ cluster or affect the secondary structure of the protein, as shown by visible circular dichroism, absorption, and attenuated total reflection Fourier transform IR spectroscopies. RFd2 presents all the EPR, visible absorption, and visible circular dichroism spectroscopic features of the $[2 \mathrm{Fe}-2 \mathrm{~S}]$ Rieske center. The cluster has a redox potential of $+48 \mathrm{mV}\left(25^{\circ} \mathrm{C}\right.$ and $\left.\mathrm{pH} 7\right)$ and a $\mathrm{p} K_{\mathrm{a}}$ of $10.1 \pm 0.2$. These shift to $+77 \mathrm{mV}$ and
\end{abstract}

Electronic supplementary material The online version of this article (doi:10.1007/s00775-009-0596-3) contains supplementary material, which is available to authorized users.

H. M. Botelho - S. S. Leal · V. Prosinecki · C. M. Gomes ( $₫)$ Instituto de Tecnologia Química e Biológica,

Universidade Nova de Lisboa,

Av. República EAN,

2780-157 Oeiras, Portugal

e-mail: gomes@itqb.unl.pt

URL: http://www.itqb.unl.pt/pbfs

A. Veith · C. Bauer · R. Fröhlich · A. Kletzin

Institute of Microbiology and Genetics,

Darmstadt University of Technology,

Schnittspahnstrasse 10,

64287 Darmstadt, Germany
$8.9 \pm 0.3$, respectively, upon reduction of the disulfide. $\mathrm{RFd} 2$ has a melting temperature near the boiling point of water $\left(T_{\mathrm{m}}=99^{\circ} \mathrm{C}, \mathrm{pH} 7.0\right)$, but it becomes destabilized upon disulfide reduction $\left(\Delta T_{\mathrm{m}}=-9^{\circ} \mathrm{C}, \Delta C_{\mathrm{m}}=-0.7 \mathrm{M}\right.$ guanidinium hydrochloride). This example illustrates how the incorporation of an additional structural element such as a disulfide bond in a highly conserved fold such as that of the Rieske domain may fine-tune the protein for a particular function or for increased stability.

Keywords Rieske ferredoxin · Iron-sulfur cluster . Disulfide $\cdot$ Protein stability $\cdot$ Thermophile

\author{
Abbreviations \\ ANS 8-Anilino-1-naphthalenesulfonic acid \\ ATR FT-IR Attenuated total reflection Fourier transform \\ infrared \\ CD Circular dichroism \\ DTNB 5,5'-Dithiobis(2-nitrobenzoic acid) \\ $\mathrm{GuHCl}$ Guanidinium hydrochloride \\ RFd2 Rieske ferredoxin 2 \\ SDS-PAGE Sodium dodecyl sulfate polyacrylamide gel \\ electrophoresis \\ TCEP Tris(2-carboxyethyl)phosphine hydrochloride \\ TPTZ 2,4,6-Tripyridyl-s-triazine \\ Tris- $\mathrm{HCl}$ Tris(hydroxymethyl)aminomethane \\ hydrochloride
}

\section{Introduction}

$\mathrm{Fe}-\mathrm{S}$ proteins are ubiquitous in all life domains and are involved in many fundamental cellular processes, from 
electron transfer, to catalysis, to regulation of gene expression. The simpler Fe-S proteins, despite their low structural complexity and small size (fewer than 150 amino acids), are able to harbor clusters with different nuclearities ([2Fe-2S], [3Fe-4S], [4Fe-4S]), or even combinations of clusters, as in the dicluster ferredoxins $([3 \mathrm{Fe}-4 \mathrm{~S}][4 \mathrm{Fe}-4 \mathrm{~S}]$ and $[4 \mathrm{Fe}-$ $4 \mathrm{~S}][4 \mathrm{Fe}-4 \mathrm{~S}])$. In these proteins the inorganic moieties are generally found in a single domain, having rather conserved topologies [1]. The protein fold and the Fe-S clusters have an intertwined contribution to the structural stability of these proteins: whereas polypeptide scaffolding provides a relatively rigid and protective ligand environment for cluster binding, the chemical stability of the Fe-S cluster itself has a key stabilizing effect on the structure.

The conserved folds of simple $\mathrm{Fe}-\mathrm{S}$ proteins are in some cases decorated by additional structural elements that somehow broaden and shape the structural and functional landscape of these proteins. Examples include $\mathrm{N}$ - and C-terminal amino acid extensions within dicluster ferredoxins [2, 3], insertion of a structural zinc site [4], and incorporation of a disulfide bond within the fold [5-7]. For instance, dicluster [3Fe-4S][4Fe-4S] ferredoxins [3] contain an N-terminal extension, which modulates the protein stability either by hosting an additional His/Asp zinc center [4, 8] or by creating a stabilizing hydrophobic core [9]. Also, a disulfide bond has been shown to contribute significantly to the stability of the [2Fe-2S] plant-type ferredoxin from the hyperthermophilic bacterium Aquifex aeolicus, as its presence increases the melting temperature from 113 to $121{ }^{\circ} \mathrm{C}$ [6]. One last example is given from the respiratory-type Rieske proteins, in which a strictly conserved disulfide in the immediate vicinity of the [2Fe-2S] cluster (within $5 \AA$ ) stabilizes the cluster binding loops and modulates the redox potential [10].

In this context, Rieske proteins are interesting examples of the functional and structural diversity within a family of proteins that share the same basic all- $\beta$ fold $[1,11]$. These proteins have the distinct feature of harboring a [2Fe-2S] cluster coordinated by two cysteine and two histidine residues. Like in other $\mathrm{Fe}-\mathrm{S}$ proteins, a considerable diversity is allowed at the level of the primary structure without disturbing the structural topology, whereas the type of amino acid side chains and the electrostatic environment found around the $[2 \mathrm{Fe}-2 \mathrm{~S}]$ Rieske cluster modulate the redox potential of the center. This results in a broad range of functional potentials, from around $-150 \mathrm{mV}$ for the soluble Rieske ferredoxins from the dioxygenase components [12], to up to $+400 \mathrm{mV}$ for the photosynthetic or respiratory Rieske domains [13, 14]. Subsequent to a thorough phylogenetic analysis $[11,15]$, the diversity of Rieske proteins was considerably expanded, in particular, concerning the soluble Rieske-type ferredoxins, as many novel sequences were identified mostly within phyletically distant organisms from the Archaea domain. Subsequent analysis using complete genome data has allowed the establishment of the existence of evolutionarily related sequences within Thermoprotei, an archaeal class comprising hyperthermoacidophilic organisms belonging to the Sulfolobus and Caldisphaera genera [16]. The genes identified encode for proteins with the typical Rieske fingerprint, but with very little amino acid identity toward other Rieske proteins. Here we report a novel structural feature within the all- $\beta$ Rieske fold, which was identified upon studying one of these as-yet uncharacterized archaeal Rieske ferredoxins from Acidianus ambivalens (EMBL FN557298). It consists of a disulfide bond within the Rieske fold, whose redox status influences the properties of the $[2 \mathrm{Fe}-2 \mathrm{~S}]$ center and simultaneously stabilizes the protein. This particular disulfide is a novel feature within Rieske proteins, and is unrelated to the disulfides described in respiratory and photosynthetic Rieske domains [17] and in the archaeal respiratory-type SoxF [5] and sulredoxin [18] proteins, which have distinct locations in the fold. This finding illustrates how minor structural modifications modulate protein function and stability and is key to rationalizing the evolutionary adapation of simple $\mathrm{Fe}-\mathrm{S}$ proteins to distinct conditions and to understanding how relatively simple folds may be finetuned for a particular function or for increased stability.

\section{Materials and methods}

\section{Sequence comparison}

Homologous Rieske amino acid sequences were extracted from the nonredundant protein database using BLAST and A. ambivalens Rieske ferredoxin 1 (Genbank 22204177) and Rieske ferredoxin $2(\mathrm{RFd} 2)$, Sulfolobus tokodaii sulredoxin, and $S$. solfataricus archaeal Rieske ferredoxins as seeds. All organisms were included in the search. We considered the hits with $E$ values of less than $10^{-10}$ to be significant. Sequences were aligned using ClustalX [19], MAFFT (http://align.bmr.kyushu-u.ac.jp/mafft/online/ server/) [20], GeneDoc [21], and CINEMA (http://www. bioinf.manchester.ac.uk/dbbrowser/CINEMA2.1/) [22]. Dendrograms were calculated using the MAFFT server and displayed using PhyloWidget (http://www.phylowidget. org/). The nucleotide sequence of the $r f d 2$ gene was submitted to the EMBL database and was assigned the accession number FN557298.

\section{Chemicals}

All reagents were of the highest grade available commercially. Guanidinium hydrochloride $(\mathrm{GuHCl})$ was obtained from Promega and the accurate concentration of its 
solutions was determined by refractive index measurements. 8-Anilino-1-naphthalenesulfonic acid (ANS), tris(2carboxyethyl)phosphine hydrochloride (TCEP), and 5,5'dithiobis(2-nitrobenzoic acid) (DTNB) were purchased from Sigma.

\section{Cloning, expression, and purification}

Acidianus ambivalens DSMZ 3772 was grown aerobically and anaerobically according to published procedures [23]. The gene encoding RFd2 was PCR-amplified from A. ambivalens genomic DNA using the following N-terminal and C-terminal primers: TATTT CATGA TTAAG ACAAT TCTTT ATGAA and AAACA ACTCG AGTGT ACCTT TTCTA GGTAA TTC, respectively. The N-terminal primer swapped the native presumable GTG start codon for an ATG. The 336-bp PCR product was digested with $B s p \mathrm{HI}$ and $\mathrm{XhoI}$ and ligated into the $\mathrm{NcoI} / \mathrm{XhoI}$-digested vector pET28a (Novagen, now Merck Biosciences, Darmstadt, Germany), thus adding two amino acid codons for the XhoI restriction site and a $\mathrm{C}$-terminal His-tag to the native protein (...LEHHHHHH). The protein was produced after isopropyl $\beta$-D-thiogalactopyranoside induction at an optical density of 0.6-1 in Escherichia coli BL21 CodonPlus RIL DE3 cells (Stratagene, now Agilent Technologies) grown overnight at $37{ }^{\circ} \mathrm{C}$ in Luria-Bertani medium supplemented with $1 \times 10^{-3}$ vol of a $100 \mathrm{mM}$ ferric chloride in $100 \mathrm{mM}$ citric acid solution. E. coli cells ( $40 \mathrm{~g})$ were resuspended after harvesting in $400 \mathrm{ml}$ of $40 \mathrm{mM}$ potassium phosphate buffer $\mathrm{pH} 8$ containing $300 \mathrm{mM} \mathrm{NaCl}$ and $10 \mathrm{mM}$ imidazole. The cells were broken using a continuous French press (Constant Systems, Daventry, UK) followed by two centrifugation steps $(15 \mathrm{~min}$ at $15,000 \mathrm{~g}$ and $60 \mathrm{~min}$ at $150,000 \mathrm{~g}$, respectively). Two hundred milliliters of the clear supernatant was applied to a 20-ml nickel nitrilotriacetic acid column (Qiagen, Hilden, Germany) equilibrated with the same buffer and connected to a fast protein liquid chromatography instrument (Pharmacia, now GE Health Care, Freiburg, Germany). The column was washed with 3 vol of $50 \mathrm{mM}$ imidazole and finally the contents were eluted with $500 \mathrm{mM}$ imidazole, both in the same buffer. The colored fractions were combined and dialyzed against $40 \mathrm{mM}$ phosphate buffer $\mathrm{pH} 8$. The sample was subsequently dialyzed against $70 \mathrm{mM}$ tris(hydroxymethyl)aminomethane hydrochloride (Tris-HCl) $\mathrm{pH} 7.7,150 \mathrm{mM} \mathrm{NaCl}$ and loaded onto a calibrated Sephadex G-50 column $(2 \mathrm{~cm} \times 50 \mathrm{~cm})$ previously equilibrated with the same buffer. Rieske ferredoxin was eluted as a pure sample as verified by sodium dodecyl sulfate polyacrylamide gel electrophoresis (SDS-PAGE) [24] and the typical UV/vis absorption spectrum. This pink stock solution was concentrated to around $1-2 \mathrm{mg} / \mathrm{ml}$ by ultrafiltration using a 5-kDa-cutoff membrane (Amicon Ultra, Millipore), flash- frozen at liquid nitrogen temperature, and stored at $-20{ }^{\circ} \mathrm{C}$ for subsequent studies. Protein was quantified using Bradford's method [25].

Disulfide reduction

The Rieske ferredoxin was purified in the oxidized state. Full reduction was achieved with excess ascorbate or sodium dithionite at room temperature. Spectra were obtained with $4.6 \mu \mathrm{M} \quad(0.06 \mathrm{mg} / \mathrm{ml})$ [far-UV circular dichroism (CD)] or $15.2 \mu \mathrm{M}(0.2 \mathrm{mg} / \mathrm{ml})($ near-UV/vis CD and absorption) protein in $2 \mathrm{mM}$ potassium phosphate $\mathrm{pH}$ 7. Low buffer concentrations are required to minimize absorption in the far-UV region. Other reduced Rieske samples were obtained by incubating $7.6 \mu \mathrm{M}$ protein with $5 \mathrm{mM}$ dithiothreitol or $5 \mathrm{mM}$ TCEP for $1 \mathrm{~h}$ in $50 \mathrm{mM}$ potassium phosphate $\mathrm{pH} 7$ at room temperature.

\section{Spectroscopic methods}

UV/vis spectra were recorded with a Shimadzu UVPC1700 spectrometer equipped with cell stirring and a Julabo water-bath-coupled thermostated cell support. Unless otherwise indicated, UV/vis absorption spectra were recorded at room temperature. $\mathrm{CD}$ measurements were performed using a JASCO J-815 spectrometer and fluorescence data were acquired with a Cary Varian Eclipse instrument, both possessing Peltier-thermostated cell supports. Attenuated total reflection Fourier transform infrared (ATR FT-IR) spectra were acquired with a Bruker IFS 66/S spectrometer equipped with a nitrogen-cooled mercury cadmium telluride detector using a water-thermostatized Harrick BioATRcell II cell. EPR spectra were acquired using a Bruker EMX spectrometer equipped with an ESR 900 continuous-flow helium cryostat at $-263{ }^{\circ} \mathrm{C}$, 9.39$\mathrm{GHz}$ microwave frequency, $2.4-\mathrm{mW}$ microwave power, and 1-mT modulation amplitude.

\section{Conformational stability}

The conformational stability of Rieske ferredoxin was assessed by performing temperature- or chemical-induced denaturation while following several spectroscopic properties: (1) visible absorption, which reports on the [2Fe-2S] cluster integrity; (2) tyrosine fluorescence, which reports on tertiary contacts; and (3) ANS fluorescence, which reports on the exposure of hydrophobic patches. Protein was prepared at $7.6 \mu \mathrm{M}$ concentration in $50 \mathrm{mM}$ potassium phosphate $\mathrm{pH}$ 7. Data treatment was performed as described in [26].

For thermal-induced denaturation, we incubated the Rieske ferredoxin with no reductant, $5 \mathrm{mM}$ TCEP, or $5 \mathrm{mM}$ dithiothreitol plus 0 or $2.5 \mathrm{M} \mathrm{GuHCl}$ at $25^{\circ} \mathrm{C}$. Then, we performed $1^{\circ} \mathrm{C} / \mathrm{min}$ temperature ramps $(25$ 
$92{ }^{\circ} \mathrm{C}$ ) while measuring the UV/vis absorption spectrum or tyrosine fluorescence at $304 \mathrm{~nm}$. The fluorimeter was set up for excitation at $275 \mathrm{~nm}$ using $10-\mathrm{nm}$ excitation and emission slits and 600-V photomultiplier tube voltage. Refolding was assessed by equilibrating the sample at $4{ }^{\circ} \mathrm{C}$ overnight (absorption) or at $25^{\circ} \mathrm{C}$ for $5 \mathrm{~min}$ (fluorescence).

$\mathrm{GuHCl}$-induced chemical denaturation curves were obtained by incubating the Rieske ferredoxin with 0 or $5 \mathrm{mM}$ TCEP and different concentrations of $\mathrm{GuHCl}$ for at least $3 \mathrm{~h}$ at room temperature. The denaturation curve corresponds to the normalized variation of fluorescence intensity at $304 \mathrm{~nm}$ or absorbance at $330 \mathrm{~nm}$. The chemical denaturation was further dissected by incubating the same samples with tenfold molar excess of ANS for at least $30 \mathrm{~min}$ at room temperature. In this case, the folding status was probed by the ANS emission band $\left(\lambda_{\mathrm{exc}}=350 \mathrm{~nm}\right)$.

\section{ATR FT-IR spectroscopy}

For ATR FT-IR spectroscopy, the Rieske ferredoxin was concentrated by ultrafiltration to $0.8 \mathrm{mM}(10.5 \mathrm{mg} / \mathrm{ml})$ in $40 \mathrm{mM}$ Tris- $\mathrm{HCl} \mathrm{pH} 7$ and then centrifuged for $30 \mathrm{~min}$ at $12,000 \mathrm{~g}$ to remove aggregates. Spectra were acquired at $20{ }^{\circ} \mathrm{C}$ and $4-\mathrm{cm}^{-1}$ resolution with 0 or $5 \mathrm{mM}$ TCEP after 3 -h equilibration. The amide I band was deconvoluted by fitting its Fourier self-deconvolution with Lorentzian curves centered at the second-derivative maxima and minima. Band assignment was performed using the reference data in [27]. The secondary structure was estimated by the Lorentzian integrals.

\section{Redox potentiometry}

The reduction potential of the $[2 \mathrm{Fe}-2 \mathrm{~S}]$ Rieske cluster was determined at $20^{\circ} \mathrm{C}$ and with $7.6 \mu \mathrm{M}$ protein in $50 \mathrm{mM}$ potassium phosphate $\mathrm{pH} 7$ with and without $5 \mathrm{mM}$ TCEP. The redox state of the Rieske [2Fe-2S] cluster was probed by the absorbance change at $490 \mathrm{~nm}$. The following redox mediators were used: 1,2-naphthoquinone-4-sulfonic acid $(+215 \mathrm{mV}, \quad 0.6 \mu \mathrm{M}), \quad 1,2$-naphthoquinone $\quad(+180 \mathrm{mV}$, $0.6 \mu \mathrm{M})$, trimethylhydroquinone $(+115 \mathrm{mV}, 0.6 \mu \mathrm{M})$, phenazine methosulfate $(+80 \mathrm{mV}, 0.6 \mu \mathrm{M}), 1,4$-naphthoquinone $(+60 \mathrm{mV}, 0.6 \mu \mathrm{M})$, 5-hydroxy-1,4-naphthoquinone (+30 mV, $0.6 \mu \mathrm{M})$, methylene blue $(+11 \mathrm{mV}, 0.79 \mu \mathrm{M})$, menadione $(0 \mathrm{mV}, \quad 0.6 \mu \mathrm{M})$, indigo tetrasulfonate $(-30 \mathrm{mV}, 0.4 \mu \mathrm{M})$, indigo trisulfonate $(-70 \mathrm{mV}, 0.55 \mu \mathrm{M})$, 2,5-hydroxy-p-benzoquinone $(-130 \mathrm{mV}, 0.23 \mu \mathrm{M})$, and 2-hydroxy-1,4-naphthoquinone $(-152 \mathrm{mV}, 0.4 \mu \mathrm{M})$; all potentials are with respect to the standard hydrogen electrode. Additionally, catalase $(0.002 \mathrm{mg} / \mathrm{ml})$, glucose oxidase $(1.6 \mathrm{U} / \mathrm{ml})$, and glucose $(0.86 \mathrm{mM})$ were added to ensure $\mathrm{O}_{2}$-free conditions. The fully oxidized protein was titrated anaerobically with buffered sodium dithionite. The sample with $5 \mathrm{mM}$ TCEP was incubated for $3 \mathrm{~h}$ at room temperature, after which time the $[2 \mathrm{Fe}-2 \mathrm{~S}]$ center had been reduced. The oxidized center was regenerated by bubbling with air. UV/vis absorption spectra were recorded during the spontaneous re-reduction of the cluster. Several oxidationreduction cycles were performed and the reduction behavior did not change, despite the progressively lower re-reduction rates (approximately 20-35 $\mathrm{mV} / \mathrm{min}$ ) due to reductant oxidation by oxygen. The titration curve includes data points from several reduction cycles. The midpoint reduction potential was determined by fitting a Nernst curve $(n=0.7$, $0 \mathrm{mM}$ TCEP; $n=1,5 \mathrm{mM}$ TCEP) to the normalized variation of absorption at $490 \mathrm{~nm}$. The lower than unity value for the $n$ value for a one-electron-acceptor center is within the experimental uncertainty and likely reflects a slight offequilibrium in that set of measurements since the visible absorption spectra of both samples are identical (Fig. S4).

\section{$\mathrm{pH}$ titration}

The $\mathrm{p} K_{\mathrm{a}}$ of the Rieske cluster was determined by investigating the $\mathrm{pH}$-associated changes of the visible $\mathrm{CD}$ spectrum. Protein samples $(11.4 \mu \mathrm{M})$ were prepared in a buffer solution composed of 2-morpholinoethanesulfonic acid, $N$-(2-hydroxyethyl)piperazine- $N^{\prime}$-ethanesulfonic acid, tricine, taurine, $N$-cyclohexyl-3-aminopropanesulfonic acid (each $10 \mathrm{mM}$ ) and $50 \mathrm{mM} \mathrm{NaCl}$ with and without $5 \mathrm{mM}$ TCEP poised at different $\mathrm{pH}$ values. The samples were equilibrated overnight at room temperature before measurement of the near-UV/vis $\mathrm{CD}$ spectrum at $25^{\circ} \mathrm{C}$. One $\mathrm{p} K_{\mathrm{a}}$ was determined by fitting the Hendersson-Hasselbalch formalism to the average normalized CD variation at 338 , $378,417,434$, and $485 \mathrm{~nm}$ (0 mM TCEP sample) or 338 , 378,462 , and $485 \mathrm{~nm}$ (5 mM TCEP sample).

Iron quantification

$\mathrm{Fe}^{2+}$ was quantitated in Rieske ferredoxin samples using the chromogenic ferrous iron chelator 2,4,6-tripyridyl-striazine (TPTZ) using a protocol adapted from [28]. Briefly, iron was released from Rieske ferredoxin by degradation in $0.9 \mathrm{M} \mathrm{HCl}$. The protein fraction was removed by precipitation in $8 \%$ trichloroacetic acid. The remaining iron solution was buffered in $16 \%$ ammonium acetate and reduced with $0.9 \%$ hydroxylamine hydrochloride. The $\mathrm{Fe}^{2+}$ concentration was then determined by the rise in the absorbance at $593 \mathrm{~nm}$ upon adding $320 \mu \mathrm{M}$ TPTZ using a calibration with iron standards.

Thiol quantification

Four Rieske samples were prepared in $100 \mathrm{mM}$ potassium phosphate $\mathrm{pH}$ 8: oxidized native, $5 \mathrm{mM}$ TCEP reduced, 
denatured in $6 \mathrm{M} \mathrm{GuHCl}$ plus $2 \mathrm{mM}$ EDTA, and denatured in $6 \mathrm{M} \mathrm{GuHCl}, 2 \mathrm{mM}$ EDTA, and $5 \mathrm{mM}$ TCEP. Protein concentrations ranged from 23 to $69 \mu \mathrm{M}$ and samples were incubated between 60 and $90 \mathrm{~min}$. After incubation, TCEPcontaining samples were desalted (HiTrap Desalting, GE Healthcare) in argon-saturated $100 \mathrm{mM}$ potassium phosphate $\mathrm{pH} 8,50 \mathrm{mM} \mathrm{NaCl}$ buffer. Then, the thiol content was determined by adding $2 \mathrm{mM}$ DTNB and recording the quantitative formation of $\mathrm{TNB}^{2-}\left(\varepsilon_{412}=14,150 \mathrm{M}^{-1}\right.$ $\left.\mathrm{cm}^{-1}\right)$. All procedures were carried at room temperature.

\section{Results and discussion}

$\mathrm{RFd} 2$ is a representative of a subtype of Rieske ferredoxins

The protein used in this study, RFd2, was identified from a search of the A. ambivalens genomic data (A. Kletzin, S.C. Schuster, J. Eck, P. Palm, D. Oesterheldt, unpublished work) using Rieske protein sequences as seeds. Among the hits was also the previously characterized Rieske ferredoxin 1 [16]. The native RFd2 is a 106 amino acid protein with a theoretical mass of $12,053 \mathrm{Da}$, and an isoelectric point of 8.9 , whereas the length of the recombinant protein is 114 amino acids, including the His-tag (13,118 Da, $\mathrm{pI}=8.6$ ). Subsequent database analysis using BLAST allowed the identification of eight significant hits $\left(E \leq 10^{-17}\right)$ related to $\mathrm{RFd} 2$, all from unannotated hypothetical proteins from the Sulfolobales and Caldisphaerales orders within the archaeal class Thermoprotei, which comprises hyperthermophilic organisms. Sequence alignment (Fig. 1) and phylogenetic analysis suggest that the latter cluster is a novel subgroup within the Rieske family (Figs. S1, S2). This group has two prominent features: one is an N-terminal truncation in a stretch which should include the $\beta 1$ strand of the Rieske fold, and the other is the presence of an additional cysteine pair in an $\operatorname{SKTPCX}_{(2-3)} \mathrm{C}$ motif at the C-terminal segment (Fig. 1), in a position that maps into a loop region in the dioxygenasetype Rieske structures [12, 29]. The sequence conservation and close proximity of these additional cysteines is

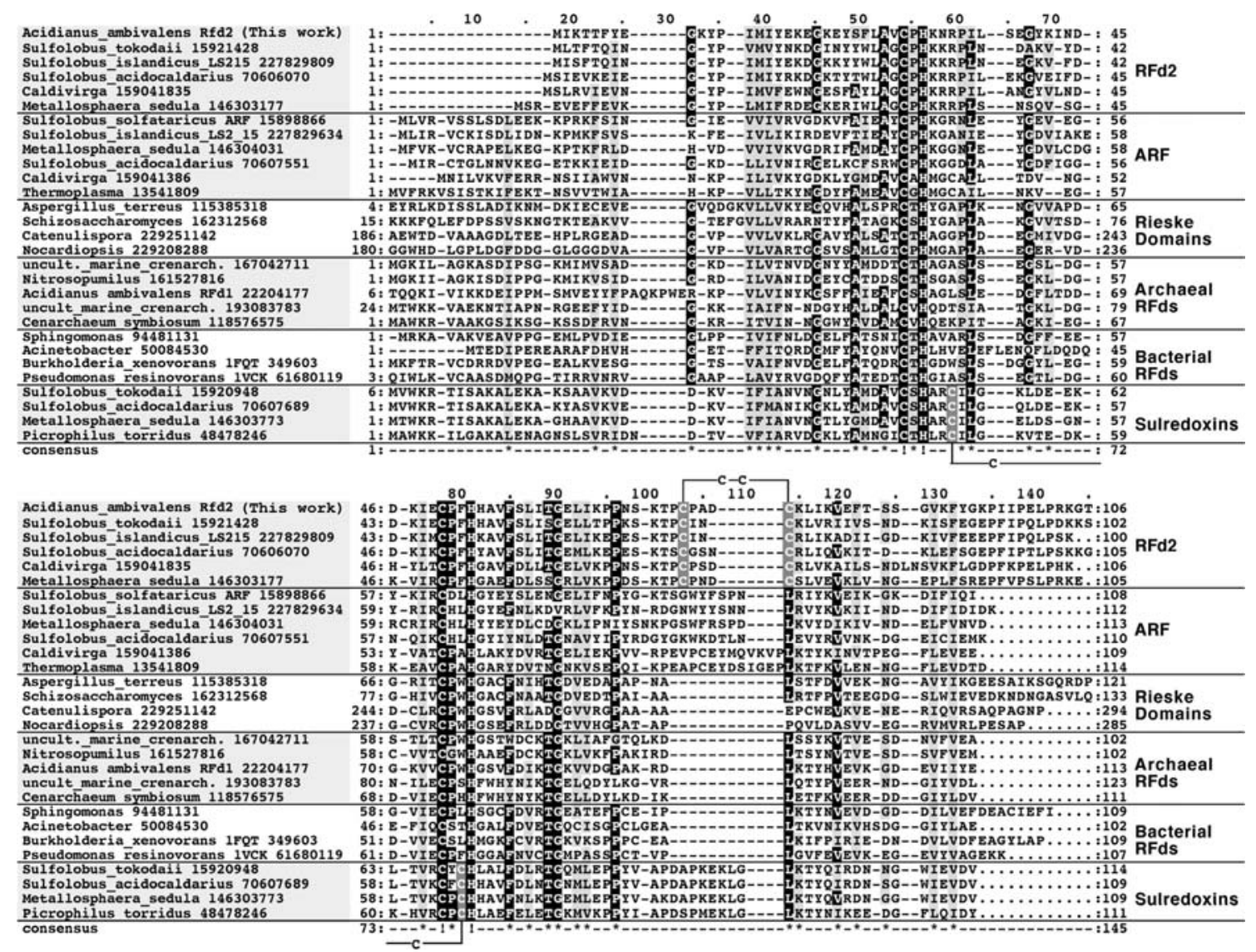

Fig. 1 Multiple sequence alignment of Rieske ferredoxins and ferredoxin domains. Lines with $C-C$ denote the Rieske ferredoxin 2 disulfide bridge and the hypothetical disulfide bridge in the sulredoxins. The latter is homologous to the disulfide from Rieske proteins from membrane-bound electron transport proteins $\left(b c_{1}\right.$ and $b_{6} f$ complexes). Numbers with species names denote the GenBank accession numbers. $R F d s$ Rieske ferredoxins, $R F d 2$ Rieske ferredoxin 2, $A R F$ archaeal Rieske ferredoxin 
suggestive of a structural role, which may involve formation of a disulfide bond or coordination of an additional metal ion, such as zinc. The $r f d 2$ gene was cloned and expressed in E. coli and the protein was purified to homogeneity using chromatographic methods. The resulting pink protein was eluted as a monomer by gel filtration chromatography and migrated in 15\% SDS-PAGE gels as being of size $14.7 \mathrm{kDa}$ (Fig. S3). Iron quantitation using the TPTZ methods determined $2.4 \pm 0.1(n=3)$ iron ions per molecule, which is compatible with the presence of an intact $[2 \mathrm{Fe}-2 \mathrm{~S}]$ cluster in the purified protein.

Spectroscopic characterization of the $\mathrm{Fe}-\mathrm{S}$ cluster in RFd2

The presence of a $[2 \mathrm{Fe}-2 \mathrm{~S}]$ Rieske cluster was clearly confirmed by subsequent biophysical analysis using UV/vis absorption, visible $\mathrm{CD}$, and EPR spectroscopies. The identity of the Rieske [2Fe-2S] center was unambiguously revealed by its characteristic EPR spectrum in the reduced form. It consists of a rhombic signal characterized by $g$ values of $g_{x}=1.80, g_{y}=1.90$, and $g_{z}=2.01$ (Fig. 2a). The average $g$ value is 1.905 , typical for [ $2 \mathrm{Fe}-2 \mathrm{~S}$ ] clusters containing nitrogen ligands and significantly lower than the value around 1.96 for plant-type [2Fe-2S] clusters. As expected for an integer-spin system, no signal was observed in the as-prepared, oxidized protein. The UV/vis absorption spectrum exhibits characteristic bands at 337, 456, and $570 \mathrm{~nm}$, and a shoulder at $490 \mathrm{~nm}$ (Fig. 2b). The $\mathrm{CD}$ spectrum in the visible region has positive peaks at 418 and $483 \mathrm{~nm}$ and negative peaks at 379, 436, 528, and $569 \mathrm{~nm}$ (Fig. 2c). Altogether, the features observed by these two techniques are typical of Rieske clusters [17]. The Rieske center is readily reduced by dithionite (Fig. 2b, c; dotted lines) and partly reduced by ascorbate (Fig. 2b, c; dashed lines), indicating that the redox potential of the center has a positive value (see later).

The cysteines in the C-terminal $\operatorname{SKTPCX}_{(2-3)} \mathrm{C}$ motif form a disulfide bridge

To address a possible role for the additional pair of cysteines (Cys-74 and Cys-78) from the $\operatorname{SKTPCX}_{(2-3)} \mathrm{C}$ motif in disulfide formation, we quantified the free thiols $(-\mathrm{SH})$ in RFd2, under different conditions, using the DTNB assay (Fig. 3). The protein contains a total of four cysteine residues, two of which are involved in the coordination of the [2Fe-2S] Rieske cluster (Cys-29 and Cys-50). The asprepared protein was found to contain no free thiols (less than $0.1 \mathrm{SH} \mathrm{mol}^{-1}$ ), which shows that under these conditions cysteines are unavailable to the DTNB reagent (Fig. 3, scheme 1). At the other extreme, in a preparation in which RFd2 was unfolded under reducing conditions and cluster disassembly was further promoted by the presence of EDTA, a total of $3.5 \pm 0.3 \mathrm{SH} \mathrm{mol}^{-1}$ was quantified. This corresponds to all cysteines in the protein becoming available to the DTNB reagent (Fig. 3, scheme 4). On the other hand, under the same denaturing conditions, if the reductant is omitted, only $1.6 \pm 0.2 \mathrm{SH} \mathrm{mol}^{-1}$ is quantified. The result is that under these conditions the clusterbinding cysteines become available, whereas Cys-74 and Cys-78 are not, thus confirming that they are involved in a disulfide (Fig. 3, scheme 3). Additional control experiments were carried out in which the cluster-binding cysteines and those from the $\operatorname{SKTPCX}_{(2-3)} \mathrm{C}$ motif were selectively reduced. This was possible since we have observed that incubation of RFd2 with $5 \mathrm{mM}$ TCEP is enough to reduce the disulfide bond $\left(1.5 \pm 0.2 \mathrm{SH} \mathrm{mol}^{-1}\right.$; Fig. 3, scheme 2) without reducing the Fe-S cluster, as the visible absorption spectrum remains unchanged even after
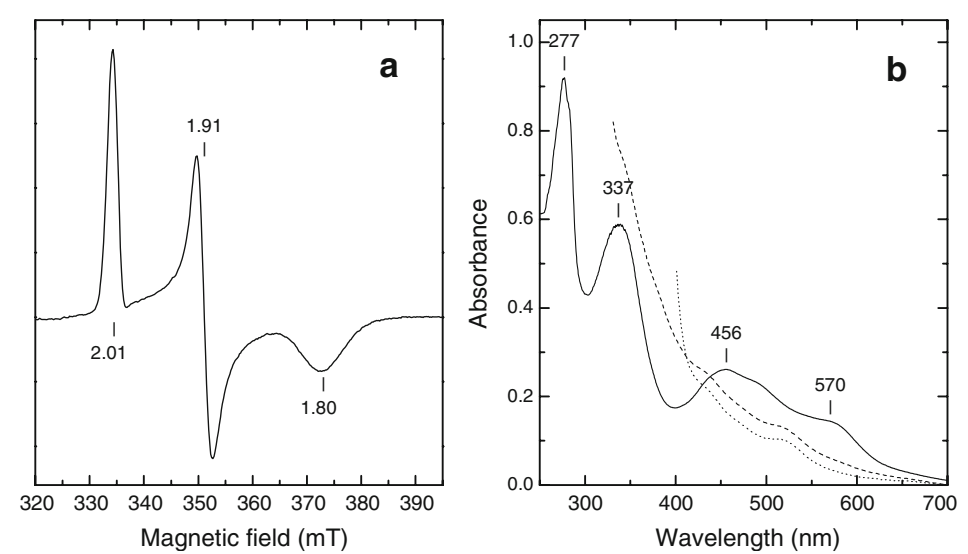

Fig. 2 Spectroscopic analysis of the Rieske cluster. a EPR spectrum of the dithionite-reduced Rieske ferredoxin at $-263{ }^{\circ} \mathrm{C}, 9.39-\mathrm{GHz}$ microwave frequency, $2.4-\mathrm{mW}$ microwave power, and 1-mT modulation amplitude. b UV/vis absorption spectra of the oxidized (continuous line), ascorbate-reduced (discontinuous line), and dithionite-reduced (dotted line) protein; $\mathrm{Abs}_{337 \mathrm{~nm}} / \mathrm{Abs}_{277 \mathrm{~nm}}=0.64$. c Visible circular dichroism spectra of the oxidized, ascorbate-reduced, and dithionite-reduced protein 
Fig. 3 Thiol quantitation and the different conditions tested. $\mathrm{GuHCl}$ guanidinium hydrochloride, TCEP tris(2carboxyethyl)phosphine hydrochloride

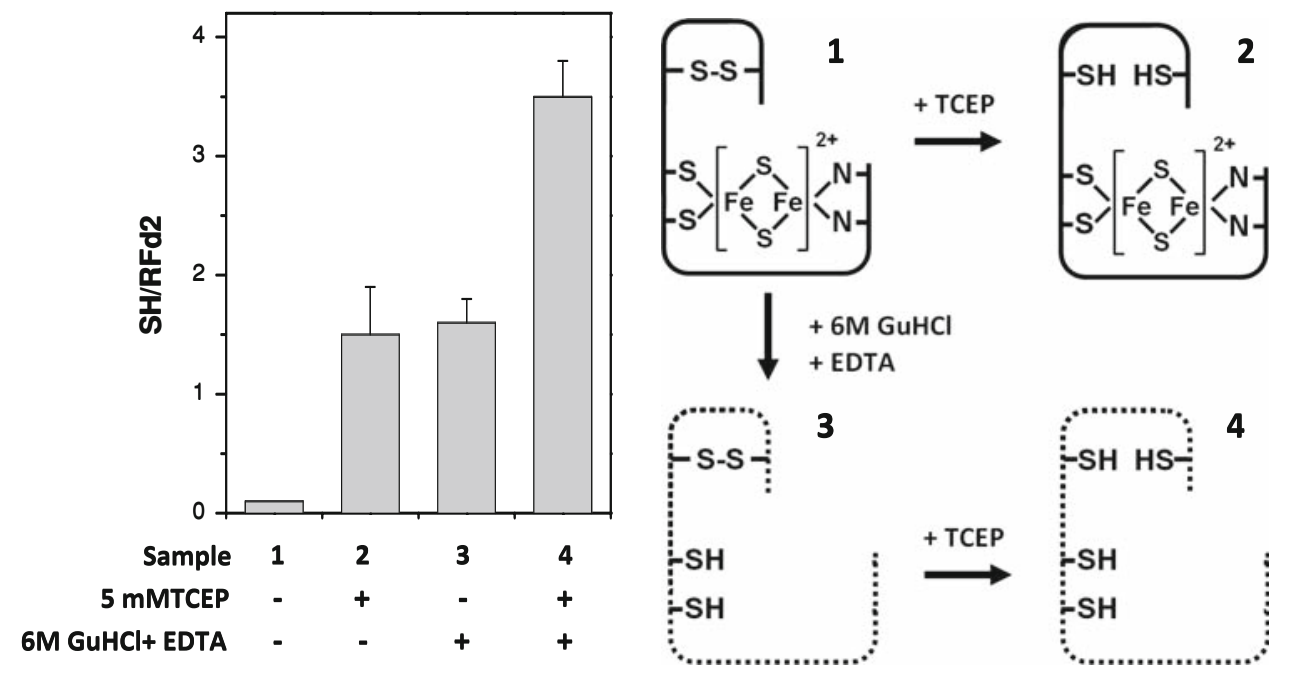

$5 \mathrm{~h}$ of incubation (Fig. S4). This provides a tool to generate a protein form in which this disulfide is selectively broken $\left(\mathrm{RFd} 2^{\mathrm{SH}}\right)$. In summary, the cysteines within the C-terminal $\operatorname{SKTPCX}_{(2-3)} \mathrm{C}$ motif are involved in a disulfide bridge, which is novel within the Rieske fold. The other types of disulfides known in Rieske proteins are discussed further later, and are found in respiratory Rieske domains, namely, on the prototypic complex III domains [17] and on the SoxF protein from $S$. acidocaldarius $[5,30]$.

The Rieske fold and secondary structure are not disrupted upon disulfide reduction

To fully characterize the role of the redox status of the disulfide bridge in the folding and the conformation of RFd2, we carried out a structural analysis using biophysical methods. CD spectroscopy was inadequate for such a study as the high content in the $\beta$-sheet of the Rieske fold accounts for a relatively featureless spectrum in the far-UV region, with a minimum around $200 \mathrm{~nm}$, typical of proteins with high amounts of random coil and no significant amounts of $\alpha$-helices, while showing the expected tertiary structure fingerprint in the near-UV region (Fig. S5). However, the multiple vibrational modes associated with $\beta$ structures produce highly informative infrared absorption spectra. For the purpose, we used ATR FT-IR spectroscopy to identify and estimate the relative amounts of each type of secondary structure element in RFd2 preparations with the disulfide in the oxidized $\left(\mathrm{RFd} 2{ }^{\mathrm{SS}}\right)$ and in the reduced $\left(\mathrm{RFd} 2{ }^{\mathrm{SH}}\right)$ states. This was achieved by deconvoluting the amide I band and carrying out assignments according to established fingerprints. This analysis showed that the spectra are nearly identical in both preparations (Fig. 4). The secondary structure of the oxidized protein (Fig. 4, plot $\mathrm{A}$ ) is composed of $43 \% \beta$-sheets, $25 \%$ random coil, $18 \%$ turns, and $8 \% \alpha$-helices, which is in a fair agreement

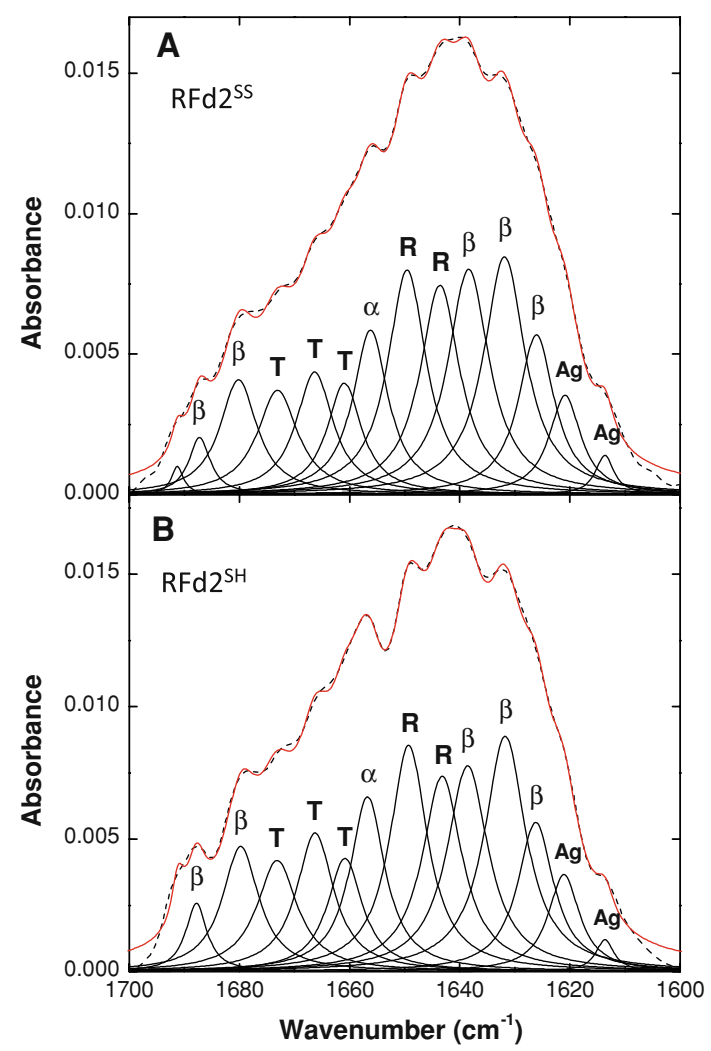

Fig. 4 Attenuated total reflection Fourier transform infrared analysis of the Rieske ferredoxin secondary structure. Self-deconvoluted spectra of Rieske ferredoxin (black dashes) in $40 \mathrm{mM}$ tris(hydroxymethyl)aminomethane $\mathrm{pH} 7$ plus $0 \mathrm{mM}$ TCEP $(A)$ or $5 \mathrm{mM}$ TCEP $(B)$. The spectra were fitted with the sum of Lorentzian curves (solid red line). The assignment of each band (solid black lines) is depicted: $\beta$-sheets $(\beta)$, unordered structures $(R), \alpha$-helices $(\alpha), \beta$-turns $(T)$, and intermolecular $\beta$-sheets $(A g)$

with the calculations made for the available Rieske structures. Around $6 \%$ of the secondary structure can be accounted for as intermolecular $\beta$-sheet contacts, which are 
usually associated with aggregation. These are, however, not significant in the overall structural content. The secondary structure changes brought about by disulfide reduction (Fig. 4, plot B) are marginal and are within the deconvolution error (Table S1). Therefore, reduction of the disulfide does not result in partial unfolding or in a loss of secondary structure.

The properties of the Rieske [2Fe-2S] cluster are influenced by the redox status of the disulfide

Redox potentiometry was used to determine the oxidationreduction potential of the [2Fe-2S] Rieske cluster, using visible absorption to monitor the reduction state of the center during an anaerobic reductive titration using dithionite. The process was reversible and a redox potential of $+48 \mathrm{mV}$ ( $\mathrm{pH} \mathrm{7)}$ was determined (Fig. 5; open circles). Taking advantage of the fact that the disulfide bond can be broken while the Rieske cluster remains oxidized, we tested if the redox properties of the cluster would be influenced by the status of the disulfide. We carried out a redox titration on the disulfide-reduced $\mathrm{RFd} 2\left(\mathrm{RFd}^{\mathrm{SH}}\right)$ and we observed that the apparent redox potential of the Rieske cluster increases by around $30 \mathrm{mV}$, to $E^{0}=+77 \mathrm{mV}(\mathrm{pH}$ 7) (Fig. 5; closed circles). These redox potentials are intermediate between those of prototypic dioxygenase-type Rieske ferredoxins $\left(E^{0} \approx-180 \mathrm{mV},[31]\right)$ and respiratory and photosynthetic Rieske domains $\left(E^{0} \approx+300 \mathrm{mV}\right.$, [17]), and this wide range has been suggested to result from differences in solvent accessibility, hydrogen bonds, and

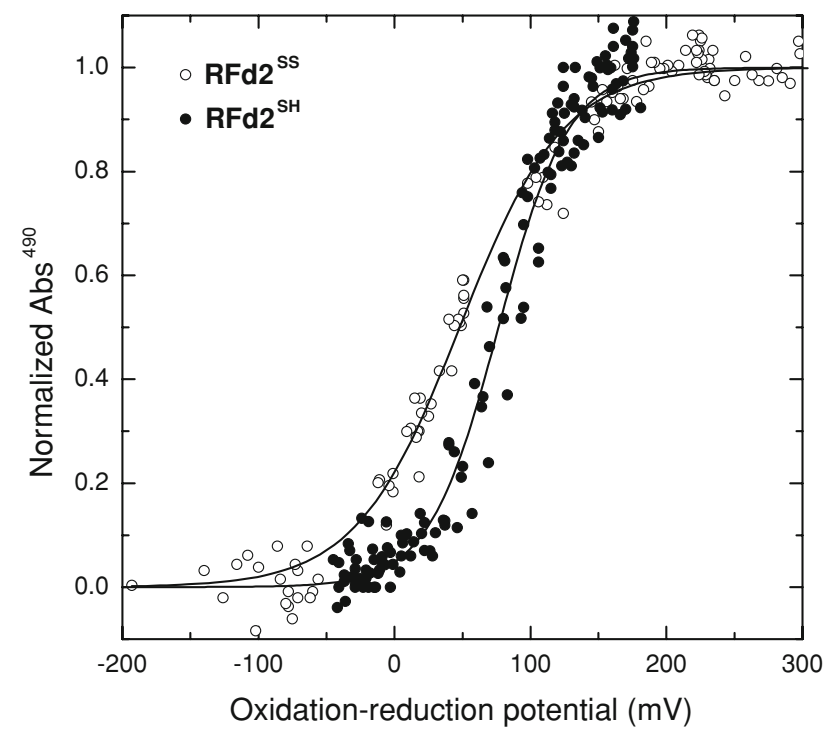

Fig. 5 Redox titration of the Rieske [2Fe-2S] center monitored by UV/vis absorption spectroscopy. The reduced fraction corresponds to the absorbance variation at $490 \mathrm{~nm}$. The fits are Nernst curves for $E^{0}=+48 \mathrm{mV}$ and $n=0.7$ (oxidized Rieske) and $E^{0}=+77 \mathrm{mV}$ and $n=1(5 \mathrm{mM}$ TCEP reduced $)$ the spatial distribution of ionizable side chains around the center among different types of Rieske proteins [29, 32]. The status of the disulfide bond also influences the redox properties of the $[2 \mathrm{Fe}-2 \mathrm{~S}]$ cluster, as its reduction results in a $30-\mathrm{mV}$ increase in the potential. This effect may arise from a change in the hydrogen-bond network around the cluster as a result of disulfide reduction. Further investigation of these factors in RFd2 will be possible when a crystal structure becomes available, as the structural model of the protein produced by I-TASSER [33] does not allow such detailed analysis.

We also investigated the influence of the redox status of the disulfide on the $\mathrm{p} K_{\mathrm{a}}$ values of the histidine ligands of the $[2 \mathrm{Fe}-2 \mathrm{~S}]$ cluster, which can be estimated from the analysis of the $\mathrm{pH}$ dependence of the visible $\mathrm{CD}$ spectrum of the Rieske center, according to a well-established procedure [34]. We used the variation of the visible CD spectra of RFd2, in the as-prepared form and in the presence of $5 \mathrm{mM}$ TCEP, from $\mathrm{pH} 6.2$ to 11.2 (Fig. S6). The data could be fit with a single transition at $\mathrm{p} K_{\mathrm{a}}=$ $10.1 \pm 0.2(0 \mathrm{mM}$ TCEP sample $)$ or $\mathrm{p} K_{\mathrm{a}}=8.9 \pm 0.3$ ( $5 \mathrm{mM}$ TCEP sample), values which are intermediate between the values reported for $b c_{1}$ Rieske proteins [34] and Rieske ferredoxins [32] in the oxidized [2Fe-2S $]^{2+}$ state. The values determined probably correspond either to a single or to an average of the two expected transitions from the two protonatable histidines, which could not be resolved. The decreased $\mathrm{p} K_{\mathrm{a}}$ in the disulfide-reduced state reflects the double-protonation event following the disulfide cleavage and constitutes additional evidence for the proximity of the intervening cysteines to the [2Fe-2S] cluster, which is responsible for the dependence of the cluster properties on the redox status of the disulfide. We have confirmed that the spectral changes observed are due to $\mathrm{pH}$-dependent modifications at the $[2 \mathrm{Fe}-2 \mathrm{~S}]$ cluster and not a result of a perturbation in the secondary structure or folding, as the far-UV CD spectra in both assays were not altered at the $\mathrm{pH}$ extremes (not shown). The presence of the C-terminal His-tag could result in a shift of the $\mathrm{p} K_{\mathrm{a}}$ values from those of the native, tagless protein. However, this hypothetical perturbation is minimized because the N-terminus and the $[2 \mathrm{Fe}-2 \mathrm{~S}]$ cluster are located on opposite sides of the Rieske fold.

The stability of RFd2 is influenced by the redox state of the disulfide

A role of the disulfide in the protein conformational stability was investigated by performing chemical and thermal unfolding experiments under conditions in which the disulfide was formed and broken. We monitored the RFd2 folding using the intrinsic fluorescence of tyrosine residues as a probe of the conformational state of the protein, as the 
protein contains no tryptophan. The chemical stability was determined as a function of the concentration of $\mathrm{GuHCl}$ in the disulfide oxidized and reduced states (Fig. 6a). From the difference in the apparent midpoint denaturant concentrations $\left(C_{\mathrm{m}}=3.7 \mathrm{M}\right.$ for $\mathrm{RFd} 2^{\mathrm{SS}}$ and $C_{\mathrm{m}}=3.0 \mathrm{M}$ for $\mathrm{RFd} 2^{\mathrm{SH}}$ ) it is clear that the disulfide increases the chemical stability of the protein. We further explored an effect of this bond on the thermal denaturation of the protein. As many other proteins of hyperthermophilic origin, RFd2 unfolds near or above the boiling point of water, as no transition is observed when the temperature is increased from 25 to $95^{\circ} \mathrm{C}$. To overcome this problem, a series of thermal denaturation transitions were determined in the presence of $\mathrm{GuHCl}$ at different concentrations, all below $C_{\mathrm{m}}$. Under these conditions, the protein becomes destabilized by the presence of denaturant, but the majority of the molecules are in the folded conformation, thus allowing the determination of an apparent midpoint denaturation temperature $\left(T_{\mathrm{m}}\right)$ at different $\mathrm{GuHCl}$ concentrations, with the disulfide intact and broken (Fig. 6b, c). Linearization plots can then be used to extrapolate $T_{\mathrm{m}}$ in the absence of denaturant, which is determined from the $y$-axis intercepts (Fig. 6d). Using this strategy, we determined that RFd2 has $\mathrm{T}_{\mathrm{m}}\left(\mathrm{H}_{2} \mathrm{O}\right)$ $=99{ }^{\circ} \mathrm{C}$, which is lowered to $91{ }^{\circ} \mathrm{C}$ when the disulfide is broken. The integrity of the Rieske [2Fe-2S] cluster was also monitored upon thermal and chemical perturbation using visible absorption spectroscopy and identical results were obtained, indicating that protein unfolding and cluster disintegration are intertwined events. Altogether, the chemical and thermal unfolding data clearly show that the disulfide involving Cys-74 and Cys-78 does have an important contribution to structural stabilization.
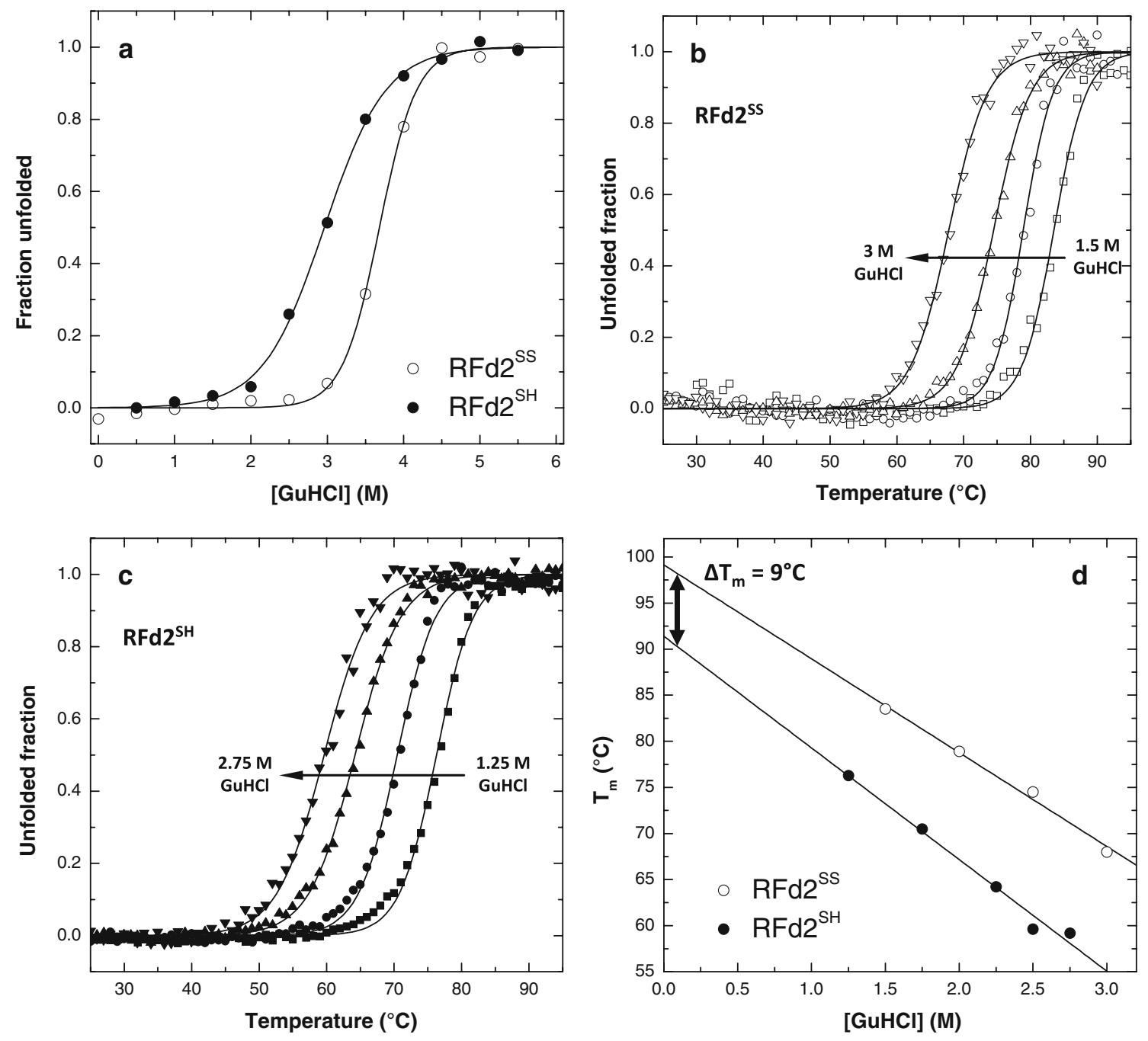

Fig. 6 Conformational stability of Rieske ferredoxin 2. a Chemical denaturation with $\mathrm{GuHCl}$. b, c Determination of the midpoint denaturation temperature $\left(T_{\mathrm{m}}\right)$ in water of the Rieske ferredoxin in

the absence (b) and presence (c) of $5 \mathrm{mM}$ TCEP, at different $\mathrm{GuHCl}$ concentrations. d Extrapolation plots for determination of $T_{\mathrm{m}}$ in water 


\section{Conclusions}

Rieske proteins are present in the three domains of life, and are found to be involved in electron transfer processes associated with different cellular processes, including respiration, photosynthesis, and dioxygenase systems [17, 35]. In recent years, studies on Rieske proteins from phylogenetically distant organisms, such as hyperthermophilic archaea [15], have elicited proteins with particular features which enlarge the structural and functional diversity of Rieske domains. In fact, there are proportionally fewer Rieske proteins known in Archaea (approximately 100) than in Eukarya (more than 450) or in Bacteria (more than 3,500), as currently listed in Pfam [36]. Here we reported the characterization of a new subtype of soluble Rieske ferredoxin of hyperthermophilic origin: essentially, this protein contains all typical fingerprints of Rieske domains in respect of the biophysical properties of its $[2 \mathrm{Fe}-2 \mathrm{~S}]$ cluster. However, it harbors a disulfide bond at the C-terminal region which has not yet been identified among the Rieske family, whose redox status affects the stability of the protein fold and of the $\mathrm{Fe}-\mathrm{S}$ cluster, the redox properties of the latter, and the $\mathrm{pH}$-associated properties of the cluster ligands. Upon its disruption, a decrease in the chemical $\left(\Delta C_{\mathrm{m}}=-0.7 \mathrm{M} \mathrm{GuHCl}\right)$ and thermal $\left(\Delta T_{\mathrm{m}}=\right.$ $-9{ }^{\circ} \mathrm{C}$ ) stabilities, an increase in the redox potential of the [2Fe-2S] center $\left(\Delta E^{0}=+31 \mathrm{mV}\right)$, and a decrease of the $\mathrm{p} K_{\mathrm{a}}$ of the histidine ligands (1.2 units) are observed, likely as a result of a rearrangement of the electrostatic, hydrogen-bonding, and covalent network around the metal cluster environment.

Rieske proteins are believed to have the same structural fold, which consists of two all- $\beta$ subdomains: one conserved small domain which has a rubredoxin-like fold, and a larger domain which consists of six $\beta$-stands packed in either a sandwich of two three-stranded sheets or a closed barrel [17]. RFd2 typifies a new subtype of Rieske ferredoxins in which the Rieske fold is decorated by a novel disulfide bond which involves a cysteine pair located at the protein Cterminus, within an $\operatorname{SKTPCX}_{(2-3)} \mathrm{C}$ motif. This motif appears as an insertion within a region that corresponds to a loop in dioxygenase Rieske proteins, and is present in five other sequences from Archaea, which share a rather high amino acid identity (approximately 37-52\%) among themselves, but not against other types of Rieske proteins (less than $15 \%$ ). The disulfide bond now identified within this family is a novel structural feature in the Rieske fold, and is unrelated to the disulfides described in respiratory and photosynthetic Rieske domains [17] and in the archaeal respiratory-type SoxF [5], whose cysteines are intertwined within the $\mathrm{Fe}-\mathrm{S}$ binding motif (CXHXXC...CPCH), and the one presumed to be present in sulredoxin [18].
The novel disulfide described within the conserved Rieske fold may underlie a stabilization strategy complementary to others found in highly thermostable proteins, which range from extensive hydrogen-bonding and saltbridge networks, to oligomerization, to reduction of loop lengths, to the formation of tightly packed hydrophobic cores. In fact, the destabilization observed upon disulfide reduction is likely a consequence of the clipping effect exerted by the bond, as the motif containing the disulfide is inserted in a loop, which is also present in a shorter version in the dioxygenase Rieske ferredoxins. Insertion of disulfide bonds to cross-link different parts of the polypeptide chain with stabilizing effects is a frequent stabilizing strategy of local structures, and in fact thermophiles are predicted to contain a higher density of disulfide bonds than mesophiles [37]. Apart from the examples within the Rieske family discussed, other small $\mathrm{Fe}-\mathrm{S}$ proteins also have a disulfide bond included in the protein structure. Those are the cases of the $[3 \mathrm{Fe}-4 \mathrm{~S}]$ ferredoxin II from Desulfovibrio gigas [7], the [4Fe-4S] ferredoxin from Thermotoga maritima, and the plant-type $[2 \mathrm{Fe}-2 \mathrm{~S}]$ ferredoxin from A. aeolicus [6]. However, with the exception of the latter, the influence of disulfide on the protein stability has not been systematically investigated.

Overall, the work reported here illustrates how minor structural modifications modulate protein function and stability, and contributes to an understanding of how relatively simple folds may be fine-tuned. Further, the characterization of a subtype of Rieske proteins present in organisms rooting deeply in the tree of life is necessary to understand the evolutionary aspects of this fold, which is ubiquitous in nature.

Acknowledgments This work was supported by grants PTDC/QUI/ 70101/2006, POCTI/QUI/45758, and POCI/BIO/58465 (to C.M.G.) from the Fundação para a Ciência e Tecnologia (FCT/MCTES), Portugal. H.M.B. (SFRH/BD/31126/2006), S.S.L. (SFRH/BD/18653/ 2004 and SFRH/BPD/47477/2008/), and V.P. (SFRH/BD/18746/ 2004) are recipients of fellowships from FCT/MCTES.

\section{References}

1. Meyer J (2008) J Biol Inorg Chem 13:157-170

2. Gao-Sheridan HS, Pershad HR, Armstrong FA, Burgess BK (1998) J Biol Chem 273:5514-5519

3. Gomes CM, Faria A, Carita JC, Mendes J, Regalla M, Chicau P, Huber H, Stetter KO, Teixeira M (1998) J Biol Inorg Chem 3:449-507

4. Fujii T, Hata Y, Wakagi T, Tanaka N, Oshima T (1996) Nat Struct Biol 3:834-837

5. Bönisch H, Schmidt CL, Schäfer G, Ladenstein R (2002) J Mol Biol 319:791-805

6. Meyer J, Clay MD, Johnson MK, Stubna A, Munck E, Higgins C, Wittung-Stafshede P (2002) Biochemistry 41:3096-3108 
7. Kissinger CR, Adman ET, Sieker LC, Jensen LH, LeGall J (1989) FEBS Lett 244:447-450

8. Kojoh K, Matsuzawa H, Wakagi T (1999) Eur J Biochem 264:85-91

9. Rocha R, Leal SS, Teixeira VH, Regalla M, Huber H, Baptista AM, Soares CM, Gomes CM (2006) Biochemistry 45:1037610384

10. Merbitz-Zahradnik T, Zwicker K, Nett JH, Link TA, Trumpower BL (2003) Biochemistry 42:13637-13645

11. Schmidt CL, Shaw L (2001) J Bioenerg Biomembr 33:9-26

12. Colbert CL, Couture MM, Eltis LD, Bolin JT (2000) Structure 8:1267-1278

13. Denke E, Merbitz-Zahradnik T, Hatzfeld OM, Snyder CH, Link TA, Trumpower BL (1998) J Biol Chem 273:9085-9093

14. Holton B, Wu X, Tsapin AI, Kramer DM, Malkin R, Kallas T (1996) Biochemistry 35:15485-15493

15. Schmidt CL (2004) J Bioenerg Biomembr 36:107-113

16. Kletzin A, Ferreira AS, Hechler T, Bandeiras TM, Teixeira M, Gomes CM (2005) FEBS Lett 579:1020-1026

17. Link TA (2001) In: Bode W, Cygler V, Messerschmidt A (eds) Handbook of metalloproteins. Wiley, Chichester

18. Iwasaki T, Imai T, Urushiyama A, Oshima T (1996) J Biol Chem 271:27659-27663

19. Larkin MA, Blackshields G, Brown NP, Chenna R, McGettigan PA, McWilliam H, Valentin F, Wallace IM, Wilm A, Lopez R, Thompson JD, Gibson TJ, Higgins DG (2007) Bioinformatics 23:2947-2948

20. Katoh K, Toh H (2008) Brief Bioinform 9:286-298
21. Nicholas KB, Nicholas HBJ, Deerfield DWI (1997) EMBnet.news 4:14

22. Parry-Smith DJ, Payne AW, Michie AD, Attwood TK (1998) Gene 221:GC57-63

23. Zillig W, Yeats S, Holz I, Bock A, Rettenberger M, Gropp F, Simon G (1986) Syst Appl Microbiol 8:197-203

24. Laemmli UK (1970) Nature 227:680-685

25. Bradford MM (1976) Anal Biochem 72:248-254

26. Pace CN, Shirley BA, Thomson JE (1990) In: Creighton T (ed) Protein structure - a practical approach. IRL Press, Oxford, pp 311-330

27. Barth A, Zscherp C (2002) Q Rev Biophys 35:369-430

28. Fischer DS, Price DC (1964) Clin Chem 10:21-31

29. Brown EN, Friemann R, Karlsson A, Parales JV, Couture MM, Eltis LD, Ramaswamy S (2008) J Biol Inorg Chem 13:1301-1313

30. Schmidt CL, Anemuller S, Schafer G (1996) FEBS Lett 388:43-46

31. Kimura S, Kikuchi A, Senda T, Shiro Y, Fukuda M (2005) Biochem J 388:869-878

32. Zu Y, Couture MM, Kolling DR, Crofts AR, Eltis LD, Fee JA, Hirst J (2003) Biochemistry 42:12400-12408

33. Wu S, Skolnick J, Zhang Y (2007) BMC Biol 5:17

34. Link TA (1994) Biochim Biophys Acta 1185:81-84

35. Bugg TD, Ramaswamy S (2008) Curr Opin Chem Biol 12:134-140

36. Finn RD, Tate J, Mistry J, Coggill PC, Sammut SJ, Hotz HR, Ceric G, Forslund K, Eddy SR, Sonnhammer EL, Bateman A (2008) Nucleic Acids Res 36:D281-D288

37. Beeby M, O'Connor BD, Ryttersgaard C, Boutz DR, Perry LJ, Yeates TO (2005) PLoS Biol 3:e309 